\section{MCN AMAn}

To the editor:

Tread Arthur Klausner's article on 1 algaculture in your November 1986 issue and was happy to see coverage finally being given to this important new field. But I was astounded to see that you neglected to mention an individual responsible for sparking much of the current interest. Christopher Hills has been a major contributor over the past 20 years in pioneering mass production of microalgae for feeding hungry people, for the nutritional products industry, and for pharmaceutical application.

Hills' companies-Biogenics, Microalgae International, Agriculture Research Co., Light Force, and Aquaculture Nutrition Products Co.-have several algae research and production facilities worldwide and have sold over \$100-million worth of Spirulina-based products over the last seven years. Hills' new research company, Phycotene Inc., is on the leading edge of algal biotechnology and has been sponsoring research at Harvard University since 1985 , including studies on using proprietary algae extracts for immune system enhancement and for cancer prevention and regression. These extracts, which contain 15 natural carotenes in addition to beta-carotene, were up to 20 times more effective than beta-carotene alone in destroying cancer cells without harm to healthy, normal cells. They also induced macrophages to produce high levels of tumor necrosis factor.

\section{Deborah Rozman Biogenics, Inc. P.O. Box 627 Santa Cruz, CA 95061}

\section{SoUR LEMots: Atmurs compunt}

\section{To the editor:}

7 he January 1987 issue of Biol Technology published a nice photograph showing juice-filled sacs, and stated "Lemon vesicles grown in tissue culture for the first time." I agree that the culture of citrus juice vesicles is, indeed, a novel approach to the biotechnological utilization of in vitro organ culture, and that it will permit scientists to perform several meaningful experiments. I would like to add, however, that this idea was conceived initially as far back as six years ago in our laboratory at the department of horticulture of the Hebrew University (Jerusalem).

In 1981 and 1982 we published a detailed description of lemon juice vesicles cultured in vitro (A. Altman et al., Physiol. Plant. 53:295-300, 1981, and Plant Physiol. 69:1-6, 1982). In addition to several photographs (which are very similar to the one shown in Bio/Technology), the papers contained a detailed procedure for the in vitro culture of juice vesicles, and they presented the results of studies on the effect of plant growth regulators on several physiological and biochemical parameters of lemon juice vesicles. Experiments currently in progress at the Otto Warburg Center for Biotechnology in Agricultures (Hebrew University, Rehovot) are aimed at further elucidating the biotechnological aspects of citrus juice vesicle culture.

Prof. A. Altman Dept. of Horticulture Hebrew University of Jerusalem

Levi Eshkol School of Agriculture Rehovot 76-100, P.O. Box 12

Israel

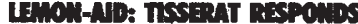

To the editor:

Culture of citrus juice vesicles has Abeen conducted by numerous investigators since the $1950 \mathrm{~s}^{1,2}$, and cultures derived from juice vesicle tissues have been used to study metabolism and differentiation ${ }^{3,4,5,6,7}$. While Dr. Altman was the first to report juice vesicle growth in culture, we believe that we are the first to achieve vesicle growth with minimal callusing (see photo in Bio/Technology 5:10, Jan. '87). To be more specific, we have routinely obtained growth (for up to six months in culture) in which the preponderance of vesicles are callusfree, with only occasional vesicles showing small areas of callus. Callusfree vesicles are important for model studies that mimic fruit-grown vesicles.

Also, we use different media, culture techniques, and growth environments than did Altman. Others using similar media to Altman's report callus production from cultured juice vesicles $^{6,7,8,9,10,11,12}$. Likewise, much callus production is evident in Altman's published photos.

Unfortunately, brief news stories such as the one in question do not allow for these kinds of details and distinctions. We assure Dr. Altman that his two papers will be fully referenced and discussed in our forthcoming technical papers.

Brent Tisserat Research Geneticist USDA Agricultural Research Service Fruit and Vegetable Chemistry Lab 263 South Chester Avenue Pasadena, CA 91106

\section{References}

1. Kordan, H. A. 1959. Proliferation of excised juice vesicles of lemon in vitro. Science 129:779-780.

2. Schroader, C. A. 1958. Some aspects of fruit tissue culture as related to developmental morphology. Indian J. Hort. 15:267-274.

3. Altman, A., Gulsen, Y., and Goren, R. 1982. Growth and metabolic activity of lemon juice vesicle explants in vitro. Plant Physiol. 69:1-6.

4. Gulsen, Y., Altman, A., and Goren, R. 1981. Growth and development of citrus pistils and fruit explants in vitro. Physiol. Plant. 53:295-300.

5. Kordan, H. A. 1975. Vacuolar physiology as an intrinsic barrier against injury-induced mitosis in lemon fruit cells. The Nucleus 18:109-118.

6. Murashige, T., and Tucker, D. P. H. 1969. Growth factor requirements of citrus tissue culture. Proc. First Intern. Citrus Symp. 3:1155-1160.

7. Tucker, D. P. H., and Murashige, T 1968. High temperature growth effects on Citrus limon fruit tissue as studies in vitro. J. Hort. Sci. 43:453461.

8. Einset, J. W. 1978. Citrus tissue culture. Plant Physiol. 62:885-888.

9. Erner, Y., Reuveni, O., and Goldschmidt, E. E. 1975. Partial purification of a growth factor from orange juice which affects citrus tissue culture and its replacement by citric acid. Plant Physiol. 56:279-282.

10. Kato, Y. 1980. Studies on juice vesicles isolated from mature and immature citrus fruit. J. Japan Soc. Hort. Sci. 49(1):36-40.

11. Kulshrestha, V. K., Chauhan, Y. S., and Roberts, L. W. 1982. In vitro studies on xylogenesis in citrus fruit vesicles-I. Effects of auxin, cytokinin and citric acid on induction of xylem differentiation. Phytomorphology 32:14-17.

12. Unger, J. W., and Feng, K. A. 1978 Growth and differentiation of juice vesicles or orange grown in vitro. Amer. J. Bot. 65:511-515. 